\title{
Expression and interaction of TNF- $\alpha$ and VEGF in chronic stress-induced depressive rats
}

\author{
BAOHUA LI ${ }^{1}$, BIN WANG $^{1}$, MIN CHEN $^{2}$, GONGYING $^{2}{ }^{2}$, MAOSHENG FANG $^{3}$ and JINGUO ZHAI ${ }^{2}$ \\ ${ }^{1}$ Department of Psychiatry, Jining Psychiatric Hospital, Jining, Shandong 272051; ${ }^{2}$ Department of Psychiatry, \\ School of Mental Health, Jining Medical University, Jining, Shandong 272067; \\ ${ }^{3}$ Wuhan Mental Health Center, Wuhan, Hubei 430022, P.R. China
}

Received July 13, 2014; Accepted May 8, 2015

DOI: $10.3892 /$ etm.2015.2641

\begin{abstract}
The incidence of depression increases annually but the pathogenesis is not yet fully understood. The aim of the present study was to explore the expression and interaction of tumor necrosis factor- $\alpha$ (TNF- $\alpha$ ) and vascular endothelial growth factor (VEGF) in chronic stress-induced depressive rats. A total of 20 adult healthy Sprague Dawley rats (180-220 g) were randomly divided into the control and experimental depression groups. The depression model was established with a chronic stress method, and the success of model construction was assessed through weigh measurements and the sugar consumption and open-field tests. The expression of TNF- $\alpha$ and VEGF was detected using the reverse transcription quantitative polymerase chain reaction (RT-qPCR), western blotting and immunohistochemistry. Compared with the control group, the weight of the rats in the experimental group was found to be reduced $(\mathrm{P}<0.05)$. The open-field test showed significant differences in the horizontal and vertical motion of the rats between the two groups, and the rats in the experimental group exhibited a significantly reduced ability to adapt to a new environment $(\mathrm{P}<0.05)$. Furthermore, the sensitivity of the rats in the experimental group to reward stimulation was decreased. The relative mRNA expression levels of TNF- $\alpha$ and VEGF in the hippocampus of the experimental group were lower than those in the control group, and western blot analysis revealed that the protein expression of VEGF and TNF- $\alpha$ was reduced in the experimental group. Neurons of the experimental group exhibited reduced immunohistochemical staining compared with neurons from the normal hippocampus in the control group. In conclusion, the present study investigated the association between the occurrence of depression and TNF- $\alpha$ and VEGF at the mRNA and protein levels using RT-qPCR,
\end{abstract}

Correspondence to: Professor Jinguo Zhai, Department of Psychiatry, School of Mental Health, Jining Medical University, 16 Lotus Road, Jining, Shandong 272067, P.R. China

E-mail: zhai_jinguo@163.com

Key words: depressive rat, stress, tumor necrosis factor- $\alpha$, vascular endothelial growth factor western blotting, immunohistochemistry and animal behavior experiments. The results provide a fundamental basis for follow-up clinical research.

\section{Introduction}

Depression is a common mental disorder with easy relapse. The main clinical characteristics of the condition are feeling down and cognitive dysfunction $(1,2)$. Although the incidence of depression increases annually, the pathogenesis of the disease remains poorly understood (3).

Previous studies have suggested that numerous factors are closely associated with the occurrence and outcome of depression, including neurotrophic factors in the brain and neural plasticity changes (4-6). These studies have indicated that neurotrophic factors can maintain neuronal survival and promote synaptic growth, and that the inhibition of neurotrophic factor expression in the hippocampus can result in the suppression of brain function and lead to depression. Currently, the main mechanisms of action of clinical antidepressants are to increase synaptic plasticity, increase neurotrophic factor levels in the brain and promote the survival of neurons (7).

Tumor necrosis factor- $\alpha$ (TNF- $\alpha)$ and vascular endothelial growth factor (VEGF) are closely associated with a variety of neurological functions and are involved in changes in neural plasticity and nerve regeneration; thus, TNF- $\alpha$ and VEGF have received considerable focus as potential candidate genes for depression gene therapy $(8,9)$. TNF- $\alpha$ is mainly responsible for maintenance of the immune system, homeostasis, inflammatory reactions and the defense function; however, studies have suggested that TNF- $\alpha$ can also exert a destructive effect (10). In the elderly, it has been shown that TNF- $\alpha$ is involved in the pathology of certain diseases, including chronic inflammation, autoimmune diseases and some malignant diseases, such as depression, and it is therefore possible that TNF- $\alpha$ could be considered as a target gene for depression treatment (11-13). VEGF is involved in angiogenesis and endothelial cell proliferation (14) and has been confirmed to be involved in acute episodes of depression $(15,16)$. In addition, VEGF is involved in angiogenesis, the protection of degenerating neurons and the prevention and control of brain ischemia. Furthermore, VEGF can stimulate the regeneration of neurons in the adult brain and effectively inhibit the occurrence and worsening 
of depression $(17,18)$. There are certain similarities between TNF- $\alpha$ and VEGF with regard to biological function, but it remains unclear how they are involved in the development of depression. It is therefore necessary to investigate whether TNF- $\alpha$ and VEGF act synergistically in the occurrence of depression. The aim of the present study was to explore the expression of TNF- $\alpha$ and VEGF in the hippocampus at the mRNA and protein levels and to investigate the interaction between TNF- $\alpha$ and VEGF.

\section{Materials and methods}

Establishment of depression model rats. A total of 20 adult healthy Sprague Dawley rats (Shanghai Silaike Experimental Animal Co., Ltd., Shanghai, China) weighing 180-220 g were randomly divided into the control and experimental depression groups ( $\mathrm{n}=10$ per group). The animals were maintained under a 12-h light/dark cycle, and the animal room was conditioned to a temperature of $22 \pm 2{ }^{\circ} \mathrm{C}$ and a humidity of $60 \%$. Water and feed were supplied amply. After a week, the rat model of depression was established using chronic, unpredictable stress for 21 days, with the following stimuli: Fasting, water deprivation, tail clamping ( $5 \mathrm{~min}$ ), foot-shock stress, noise, ice swimming, altered circadian rhythms and heat stimulation. Identical stimulations were separated by $>2$ days, and each stimulation was applied 2-3 times according to the principles of random arrangement. The normal animals without stimulation were used as the control group. Measurements of weight and the sugar consumption and open-field tests were used to determine the success of the model construction, and the results were analyzed statistically. For the sugar consumption experiment, rats received equivalent water and $1 \%$ sugar solution after fasting for $24 \mathrm{~h}$. The sugar consumption rate was measured after $24 \mathrm{~h}$. The rat sugar consumption rate was calculated as: Sugar consumption/(sugar consumption + water

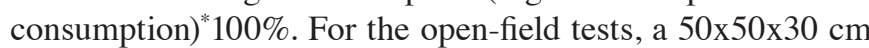
box was used, with the bottom of box divided into 25 equilateral squares. The rat was put into the center of the box bottom and the horizontal and vertical activity frequency in 5 min was recorded. The experimental methods were performed strictly in accordance with the institutional guidelines of the Animal Care and Use Committee of Jining Medical University (Jining, China).

Reverse transcription-quantitative polymerase chain reaction $(R T-q P C R)$. Total RNA was extracted according to the instructions of the RNA extraction kit manual (Invitrogen Life Technologies, Carlsbad, CA, USA), and cDNA was then prepared through RT. Thermoscript one-step quantitative RT-PCR with platinum Taq kit was used to synthesize cDNA and to perform subsequent real-time RT-qPCR (Applied Biosystems Life Technologies, Foster City, CA, USA). The expression levels of the target genes TNF- $\alpha$ and VEGF were detected using SYBR ${ }^{\circledR}$ Green-based qPCR, and the results of the fluorescence qPCR were analyzed using an Applied Biosystems 7500 Real-Time PCR System (Applied Biosystems). The primer sequences used were as follows: TNF- $\alpha$, F 5'-ATACACTGGCCCGAGGCAAC-3' and R 5'-CCA CATCTCCGGATCATGCTTTC-3'; VEGF, F 5'-GTCACTATG CAGATCATGCGGA-3' and R 5'-GTCACTATGCAGATCATG
Table I. Effect of chronic stress on the food intake and body weight of rats.

\begin{tabular}{lcc}
\hline Group & Net weight increment $(\mathrm{g})$ & Food intake $(\mathrm{g})$ \\
\hline Control & $131.11 \pm 2.05$ & $14.24 \pm 0.11$ \\
Experimental & $83.51 \pm 1.15^{\mathrm{a}}$ & $6.68 \pm 0.09^{\mathrm{a}}$ \\
\hline
\end{tabular}

${ }^{\mathrm{a}} \mathrm{P}<0.05$ vs. the control group. Results are presented as the mean \pm standard deviation; $\mathrm{n}=10$.

Table II. Effect of chronic stress on the horizontal and vertical motion scores of rats.

\begin{tabular}{lcc}
\hline Group & $\begin{array}{c}\text { Horizontal } \\
\text { motion score }\end{array}$ & $\begin{array}{c}\text { Vertical } \\
\text { motion score }\end{array}$ \\
\hline Control & $59.77 \pm 1.08$ & $13.35 \pm 0.62$ \\
Experimental & $9.79 \pm 0.83^{\mathrm{a}}$ & $5.03 \pm 0.38^{\mathrm{a}}$ \\
\hline
\end{tabular}

${ }^{\mathrm{a}} \mathrm{P}<0.05$ vs. the control group. Results are presented as the mean \pm standard deviation; $\mathrm{n}=10$.

CGGA-3'; and $\beta$-actin, F 5'-GTCGTACCACTGGCATTGTG-3' and R 5'-CTCTCAGCTGTGGTGGTGAA-3'. PCR conditions were as follows: 40 cycles of denaturation at $95^{\circ} \mathrm{C}$ for $15 \mathrm{sec}$, $60 \mathrm{sec}$ at $60^{\circ} \mathrm{C}$ annealing, and elongation with optics on for fluorescence monitoring. $\beta$-actin was used as a reference gene and the $2^{-\Delta \Delta \mathrm{CT}}$ method was used to quantify the data.

Western blot analysis. The total cellular proteins in each group were extracted. Cells were lysed in a radioimmunoprecipitation assay buffer containing $50 \mathrm{mM}$ Tris (pH 7.4), $150 \mathrm{mM} \mathrm{NaCl}$, $1 \%$ Triton X-100, $1 \%$ sodium deoxycholate, $0.1 \%$ SDS, $1 \mathrm{mM}$ EDTA and protease inhibitor cocktail (Beyotime Institute of Biotechnology, Haimen, China) for protein extraction. The total protein content was determined by bicinchoninic acid assay. Following the quantitative determination of protein content, the proteins were denatured at $100^{\circ} \mathrm{C}$ for $5 \mathrm{~min}$ and fractionated through $8 \%$ SDS-PAGE. The proteins were electrotransferred onto polyvinylidene difluoride membranes. Membranes were blocked with $5 \%$ skimmed milk for $1 \mathrm{~h}$ at room temperature. Protein expression was subsequently detected by incubation with rabbit polyclonal primary antibodies against TNF- $\alpha$ (1:100; sc-8301), VEGF (1:100; sc-507) and $\beta$-actin (Santa Cruz Biotechnology, Inc., Santa Cruz, CA, USA) at $4^{\circ} \mathrm{C}$ overnight. Following incubation with the primary antibody, the membranes were incubated with horseradish peroxidase-conjugated secondary antibody for coloration (Santa Cruz Biotechnology, Inc.) (19). The bound antibodies were visualized using an enhanced chemiluminescence reagent (EMD Millipore, Billerica, MA, USA) and quantified densitometrically using an electrophoresis image analysis system (FR980; Shanghai Furi Science \& Technology Co., Ltd., Shanghai, China). Densitometric analyses of the bands were performed with $\beta$-actin as the loading control. Triplicate experiments with triplicate samples were performed. 
Table III. Effect of chronic stress on the fluid consumption index of rats.

\begin{tabular}{|c|c|c|c|c|c|c|c|c|}
\hline \multirow[b]{2}{*}{ Group } & \multicolumn{2}{|c|}{$\begin{array}{c}\text { Total liquid } \\
\text { consumption }(\mathrm{ml} / 24 \mathrm{~h})\end{array}$} & \multicolumn{2}{|c|}{$\begin{array}{c}\text { Sugar water } \\
\text { consumption }(\mathrm{ml} / 24 \mathrm{~h})\end{array}$} & \multicolumn{2}{|c|}{$\begin{array}{l}\text { Water consumption } \\
\qquad(\mathrm{ml} / 24 \mathrm{~h})\end{array}$} & \multicolumn{2}{|c|}{$\begin{array}{c}\text { Percentage of sugar } \\
\text { water preference }(\%)\end{array}$} \\
\hline & $\begin{array}{l}\text { Before } \\
\text { stress }\end{array}$ & $\begin{array}{l}\text { After } \\
\text { stress }\end{array}$ & $\begin{array}{l}\text { Before } \\
\text { stress }\end{array}$ & $\begin{array}{l}\text { After } \\
\text { stress }\end{array}$ & $\begin{array}{l}\text { Before } \\
\text { stress }\end{array}$ & $\begin{array}{l}\text { After } \\
\text { stress }\end{array}$ & $\begin{array}{l}\text { Before } \\
\text { stress }\end{array}$ & $\begin{array}{l}\text { After } \\
\text { stress }\end{array}$ \\
\hline Control & $15.4 \pm 0.1$ & $14.7 \pm 0.1$ & $11.4 \pm 0.1$ & $11.4 \pm 0.2$ & $2.9 \pm 0.1$ & $2.9 \pm 0.1$ & $63.7 \pm 0.2$ & $62.8 \pm 0.2$ \\
\hline Experimental & $14.7 \pm 0.2$ & $13.5 \pm 0.1$ & $10.7 \pm 0.1$ & $6.9 \pm 0.1^{\mathrm{a}}$ & $3.1 \pm 0.1$ & $5.7 \pm 0.1^{\mathrm{a}}$ & $65.2 \pm 0.3$ & $62.2 \pm 0.2$ \\
\hline
\end{tabular}

${ }^{\mathrm{a}} \mathrm{P}<0.05$ vs. the control group. Results are presented as the mean \pm standard deviation; $\mathrm{n}=10$.

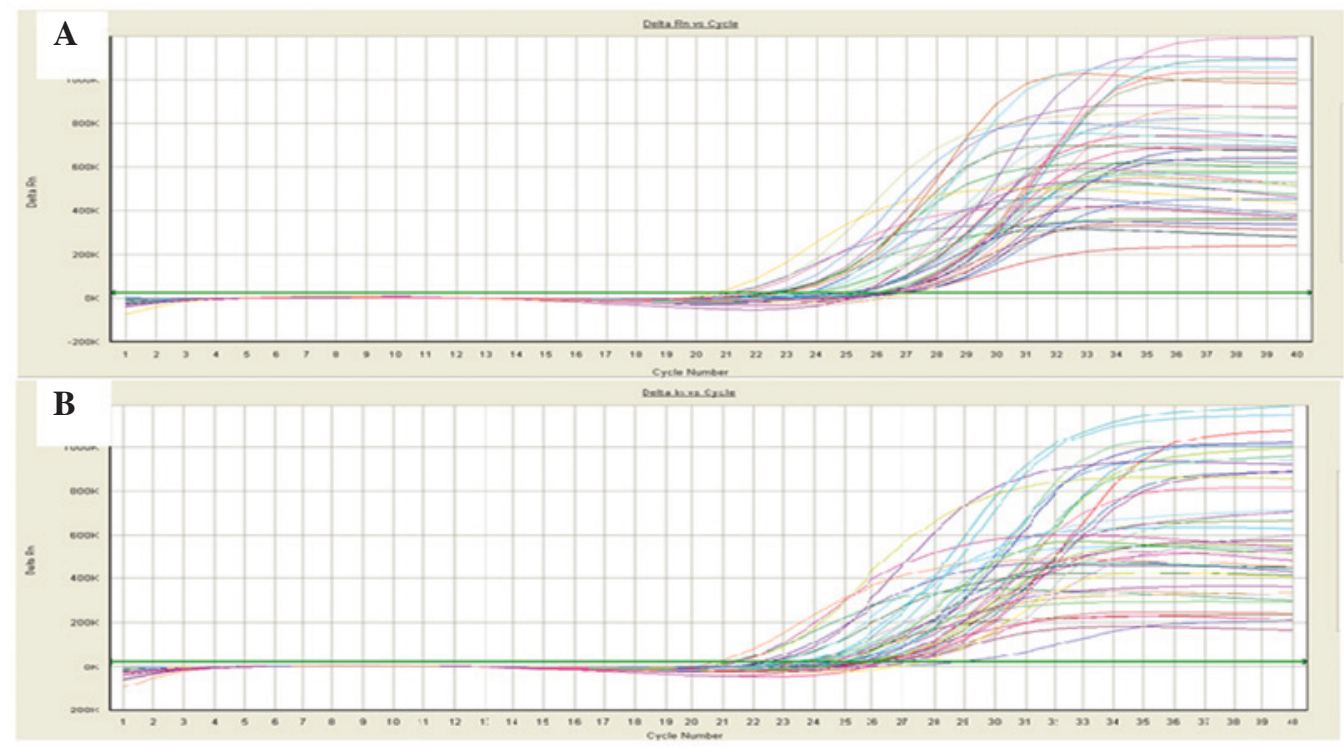

$\mathbf{C}$

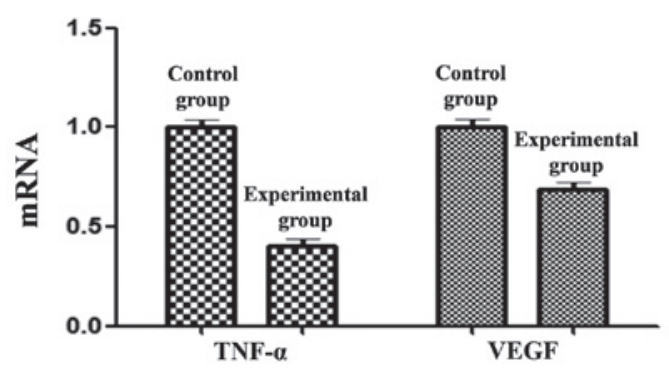

Figure 1. qPCR results for TNF- $\alpha$ and VEGF. (A and B) Amplification curves for (A) TNF- $\alpha$ and (B) VEGF (the vertical coordinate stands for the Log values of the cDNA concentration of VEGF and TNF- $\alpha$, and the abscissa stands for the corresponding Ct values). (C) mRNA levels of TNF- $\alpha$ and VEGF in the hippocampus, as detected by qPCR. qPCR, quantitative polymerase chain reaction; TNF- $\alpha$, tumor necrosis factor- $\alpha$; VEGF, vascular endothelial growth factor.

Immunohistochemical staining. The rats were sacrificed via spinal dislocation. Frozen slices were then prepared from brain tissue, and the slices were rinsed with phosphate-buffered saline three times, for $10 \mathrm{~min}$ each time. The endogenous peroxidase was inactivated by hydrogen peroxide. The sections underwent $0.5 \%$ potassium citrate microwave antigen retrieval at $100^{\circ} \mathrm{C}$ for $15 \mathrm{~min}$. The frozen slices were then incubated at room temperature for 10-15 min, blocked with goat serum for $30 \mathrm{~min}$ and incubated with polyclonal rabbit primary antibodies against TNF- $\alpha(1: 100)$ and VEGF $(1: 100)$ at $37^{\circ} \mathrm{C}$ for $1 \mathrm{~h}$. Following the incubation with the primary antibody, the slices were incubated with horse radish peroxidase-conjugated secondary antibody at $37^{\circ} \mathrm{C}$ for $30 \mathrm{~min}$ and then with horseradish peroxidase-conjugated fluorescent pigment at $37^{\circ} \mathrm{C}$ for 30 min. The slices were subsequently treated with 3,3'-diaminobenzidine chromogen and subjected to dehydration, clearing and mounting.

Statistical analysis. Data are presented as the mean \pm standard deviation. Comparisons between the control and experimental groups were conducted using the two-tailed Student's t-test with SPSS 18.0 software (SPSS, Inc., Chicago, IL, USA). $\mathrm{P}<0.05$ was considered to indicate a statistically significant difference. 

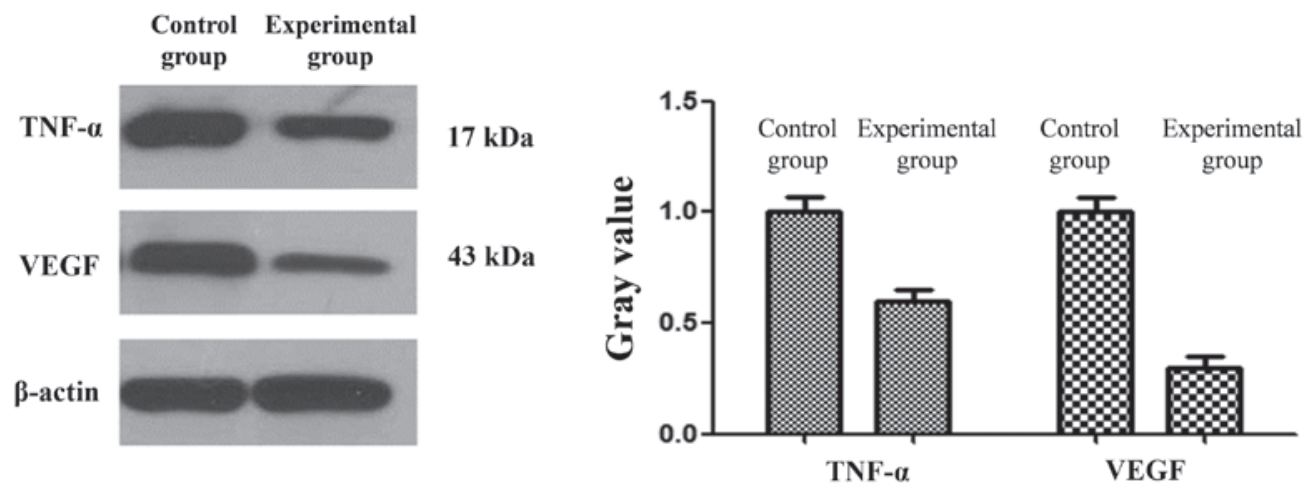

Figure 2. TNF- $\alpha$ and VEGF expression in the hippocampus following chronic stress. Gray values show the relative TNF- $\alpha$ and VEGF expression in the hippocampus between the control and experimental groups $(\mathrm{P}<0.05)$. TNF- $\alpha$, tumor necrosis factor- $\alpha$; VEGF, vascular endothelial growth factor.

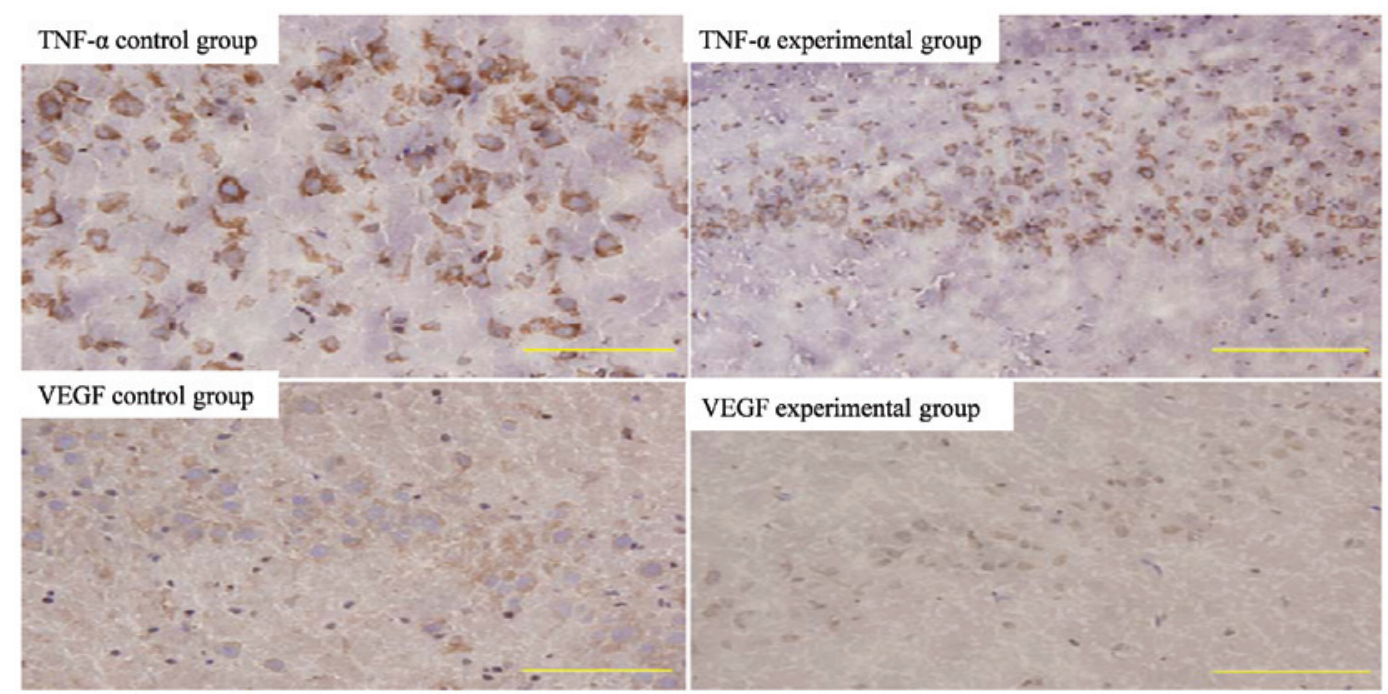

Figure 3. Immunohistochemical analysis of TNF- $\alpha$ and VEGF expression in the hippocampus of each group (magnification, x100; stain, streptavidin-peroxidase). TNF- $\alpha$, tumor necrosis factor- $\alpha$; VEGF, vascular endothelial growth factor.

\section{Results}

Results of the weight measurements and sugar water consumption and open-field tests. Prior to modeling, no significant differences were found between the two groups. Following modeling, however, the rats in the experimental group were observed to eat and weigh less and to exhibit fur shedding, reduced luster, slowness of movement and low spirits. The weight of the rats in the experimental group was significantly lower than that of the rats in the control group $(\mathrm{P}<0.05)$ (Table I). The open-field test showed that the rats in the experimental and control groups exhibited significant differences in the horizontal and vertical motion scores $(\mathrm{P}<0.05)$, and the ability of the rats in the experimental group to adapt to a new environment was significantly decreased (Table II). Significant differences were also found in the sugar consumption-related indicators between the two groups $(\mathrm{P}<0.05$; Table III), and the sensitivity of the rats in the experimental group to reward stimulation and pleasure was decreased.

$q P C R$. The qPCR showed that the relative mRNA expression levels of TNF- $\alpha$ and VEGF in the hippocampus of the experimental group were lower than those in the control group. The relative VEGF mRNA expression level of the experimental group was only half that of the control group, while the expression level of TNF- $\alpha$ was only slightly lower in the experimental group than that in the control group. The results indicated that, compared with the control group, the mRNA expression of TNF- $\alpha$ and VEGF was significantly lower in the experimental group (Fig. 1).

Western blotting. Compared with the expression of VEGF and TNF- $\alpha$ in the hippocampus in the control group, the expression was reduced in the hippocampus in the experimental group (Fig. 2). The differences between the two groups were found to be statistically significant $(\mathrm{P}<0.05)$.

Immunohistochemistry. Compared with the expression of TNF- $\alpha$ and VEGF in the normal hippocampus in the control group, the hippocampal expression of TNF- $\alpha$ and VEGF in the experimental group was reduced (Fig. 3).

\section{Discussion}

Depressive disorder, also called depression, is one of the main emotional disorders observed in the clinic. The condition can further develop and deteriorate, affecting overall physiological 
function and leading to a series of clinical symptoms, such as sleep disorders or loss of appetite (20). The rodent chronic, unpredictable, mild stress (CUMS) model was first successfully established by Willner et al in 1957 (21). This model was demonstrated to simulate the exogenous factors for the onset of depression, including reduced sensitivity to reward, lack of pleasure and behavioral and spiritual malaise (22), with the main symptoms of a reduction in the intake of sweet liquid food (21). Matthews et al (23) have proposed that weight reduction is also a clinical symptom closely associated with depression. In addition to the above characteristics, the CUMS model can be used for the simulation of human physiological bradykinesia. The open-field test can be used to verify the degree of horizontal activity of the rat (24), a reduction in which is a clinical sign associated with human depression (25). Following transferal to the new environment, the physiological activity of healthy rats will increase, as the rats familiarize themselves with the new environment; however, observation of the CUMS rat model showed that the self-regulation and vertical motion ability of the rats were markedly reduced (26). These findings indicated that the interest in the new environment was reduced for the CUMS rats, suggesting that the CUMS model exhibits characteristics similar to the clinical symptoms of human depression and therefore has significance as a biological reference (27).

In the present study, the changes in the TNF- $\alpha$ and VEGF mRNA and protein expression in the hippocampus were explored with qPCR, western blotting and immunohistochemistry. The results suggested that TNF- $\alpha$ and VEGF played a key role in the development of depression. TNF- $\alpha$ is generated in the initial stages of the inflammatory response and causes and enhances numerous reaction effects, including increasing vascular penetration and the activation of white blood cells at the site of infection and injury; due to these characteristics, TNF is considered to be the initiator of inflammation, blood vessel formation and tumor metastasis, as well as a promoting factor of tumors (28). Studies have shown that TNF- $\alpha$ is involved in the development of depression $(29,30)$. The mechanisms of antidepressant drugs have yet to be fully elucidated; however, it has been proposed that they are associated with the stimulation of growth factor signaling pathways and neurogenesis in the hippocampus (31).

The VEGF expression in the hippocampus and the effect of antidepressant drugs on the hippocampal expression of VEGF have been previously studied. The proliferation of hippocampal subgranular zone (SGZ) cells can be inhibited when the VEGF receptor Flk-1 is blocked by pharmacological methods, such as chronic exposure to fluoxetine or desipramine, or through electroconvulsive shock therapy (32). SGZ cells can be induced to proliferate following the intracerebroventricular delivery of certain types of VEGF isoforms (33). Studies have shown that TNF- $\alpha$ can promote the expression of VEGF at the mRNA and protein levels; furthermore, synergy exists between TNF- $\alpha$ and TGF- $\beta 1$ or VEGF, which can promote the repair of nerve cells $(34,35)$.

Previous studies of depression have utilized large-scale genetic screening methods, which do not facilitate the analysis of specific genes, and exhibit a lack of follow-up experiments for the screened gene (36). In the present study, the occurrence of depression was investigated at the protein and mRNA levels using western blotting, immunohistochemistry, qPCR and animal behavior experiments. The results of the study have provided a basis for follow-up clinical research.

\section{References}

1. Kessler RC Berglund P, Demler O, Jin R, Koretz D, Merikangas KR, Rush AJ, Walters EE and Wang PS; National Comorbidity Survey Replication: The epidemiology of major depressive disorder: Results from the National Comorbidity Survey Replication (NCS-R). JAMA 289: 3095-3105, 2003.

2. Wray NR, Pergadia ML, Blackwood DH, Penninx BW, Gordon SD, Nyholt DR, et al: Genome-wide association study of major depressive disorder: New results, meta-analysis, and lessons learned. Mol Psychiatry 17: 36-48, 2012.

3. McEwen BS: Plasticity of the hippocampus: Adaptation to chronic stress and allostatic load. Ann NY Acad Sci 933: 265-277, 2001.

4. Diniz BS, Teixeira AL, Machado-Vieira R, Talib LL, Gattaz WF and Forlenza OV: Reduced serum nerve growth factor in patients with late-life depression. Am J Geriatr Psychiatry 21: 493-496, 2013.

5. Streeter CC, Gerbarg PL, Saper RB, Ciraulo DA and Brown RP: Effects of yoga on the autonomic nervous system, gamma-aminobutyric-acid, and allostasis in epilepsy, depression, and post-traumatic stress disorder. Med Hypotheses 78: 571-579, 2012.

6. Cao J, Wang J, Kuang L, Chen J, Ai M, Wang W, Chen X, Lv Z and Wang H: Plasma level of brain-derived neurotrophic factor and the related analysis in depressive patients with suicide attempt. Zhong Guo Shen Jing Jing Shen Bing Za Zhi 39: 597-601, 2013 (In Chinese).

7. Smeeding SJ, Bradshaw DH, Kumpfer K, Trevithick S and Stoddard GJ: Outcome evaluation of the Veterans Affairs Salt Lake City Integrative Health Clinic for chronic pain and stressrelated depression, anxiety, and post-traumatic stress disorder. J Altern Complement Med 16: 823-835, 2010

8. Dean B, Tawadros N, Scarr E and Gibbons AS: Regionally-specific changes in levels of tumour necrosis factor in the dorsolateral prefrontal cortex obtained postmortem from subjects with major depressive disorder. J Affect Disord 120: 245-248, 2010.

9. Fournier NM and Duman RS: Role of vascular endothelial growth factor in adult hippocampal neurogenesis: Implications for the pathophysiology and treatment of depression. Behav Brain Res 227: 440-449, 2012.

10. Liu B, Xu C, Wu X, Liu F, Du Y, Sun J, Tao J and Dong J: Icariin exerts an antidepressant effect in an unpredictable chronic mild stress model of depression in rats and is associated with the regulation of hippocampal neuroinflammation. Neuroscience 294: 193-205, 2015.

11. Balkwill F: TNF-alpha in promotion and progression of cancer. Cancer Metastasis Rev 25: 409-416, 2006.

12. Kunz M, Ceresér KM, Goi PD, Fries GR, Teixeira AL, Fernandes BS, Belmonte-de-Abreu PS, Kauer-Sant'Anna M, Kapczinski F and Gama CS: Serum levels of IL-6, IL-10 and TNF- $\alpha$ in patients with bipolar disorder and schizophrenia: Differences in pro-and anti-inflammatory balance. Rev Bras Psiquiat 33: 268-274, 2011.

13. Pezoa-Jares RE, Alvarez-Sekely AM, Lopez-Bago AL, Vasquez-Medina JA, Cruz-Fuentes CS and Lascurain-LedesmaR: 1395 - Quality of life and TNF- $\alpha$ levels in Mexican patients with tuberculosis and major depressive disorder. Eur Psychiatry 28: $1,2013$.

14. Rapisarda A and Melillo G. Role of the VEGF/VEGFR axis in cancer biology and therapy. Adv Cancer Res 114: 237-267, 2012.

15. Perera TD, Coplan JD, Lisanby SH, Lipira CM, Arif M, Carpio C, Spitzer G, Santarelli L, Scharf B, Hen R, Rosoklija G, Sackeim HA and Dwork AJ: Antidepressant-induced neurogenesis in the hippocampus of adult nonhuman primates. J Neurosci 27: 4894-4901, 2007.

16. Sun ST and Zhao HQ: Relationship of VEGF and depression. Guo Ji Jing Sheng Bing Xue Za Zhi 2: 83-85, 2013 (In Chinese).

17. Chauvet S, Burk K and Mann F: Navigation rules for vessels and neurons: cooperative signaling between VEGF and neural guidance cues. Cell Mol Life Sci 70: 1685-1703, 2013.

18. Kiuchi T,Lee H and Mikami T: Regular exercise cures depressionlike behavior via VEGF-Flk-1 signaling in chronically stressed mice. Neuroscience 207: 208-217, 2012. 
19. Song G, Ouyang G, Mao Y, Ming Y, Bao S and Hu T: Osteopontin promotes gastric cancer metastasis by augmenting cell survival and invasion through Akt-mediated HIF-1alpha up-regulation and MMP9 activation. J Cell Mol Med 13: 1706-1718, 2009.

20. Frank E, Prien RF, Jarrett RB, Keller MB, Kupfer DJ, Lavori PW, Rush AJ and Weissman MM: Conceptualization and rationale for consensus definitions of terms in major depressive disorder: Remission, recovery, relapse, and recurrence. Arch Gen Psychiatry 48: 851-855 1991.

21. Willner P, Towell A, Sampson D, Sophokleous S and Muscat R: Reduction of sucrose preference by chronic unpredictable mild stress and its restoration by a tricyclic antidepressant. Psychopharmacology (Berl) 93: 358-364, 1987.

22. Barr AM, Brotto LA and Phillips AG. Chronic corticosterone enhances the rewarding effect of hypothalamic self-stimulation in rats. Brain Res 875: 196-201, 2000.

23. Matthews K, Forbes N and Reid IC: Sucrose consumption as an hedonic measure following chronic unpredictable mild stress Physiol Behav 57: 241-248, 1995.

24. Anisman $\mathrm{H}$ and Matheson K: Stress, depression, and anhedonia: Caveats concerning animal models. Neurosci Biobehav Rev 29: 525-546, 2005.

25. D'Aquila PS, Peana AT, Carboni V and Serra G: Exploratory behaviour and grooming after repeated restraint and chronic mild stress: Effect of desipramine. Eur J Pharmacol 399: 43-47, 2000.

26. Redrobe JP, Dumont Y, Fournier A, Baker GB and Quirion R: Role of serotonin (5-HT) in the antidepressant-like properties of neuropeptide Y (NPY) in the mouse forced swim test. Peptides 26: 1394-1400, 2005.

27. Cryan JF, Valentino RJ and Lucki I: Assessing substrates underlying the behavioral effects of antidepressants using the modified rat forced swimming test. Neurosci Biobehav Rev 29: 547-569, 2005.
28. Li Wei, Liu Jia, Bai Jiayuan, Gu Changqin, Zhang Wanpo, Cheng Guofu and Hu Xueying: Recent progress of tumor necrosis factor- $\alpha$. Dong Wu Yi Xue Fa Zhan 31: 108-111, 2010 (In Chinese).

29. Tian XS, Hu N, Song L, Sun ZX and Cheng W: Effects of Suanzaoren decoction on expression of TNF- $\alpha$, IL- $1 \beta$ and c-fos in hippocampus of depression rats model. Zhong Guo Yao Xue Bao 2: 44-46, 2013 (In Chinese).

30. Zhao SH, Kong JH, Yang CJ, Lin YH and Wang LZ: Effect of duloxetine on the levels of cytokines in patients with first-episode depression. Zhong Guo Xing Wei Yi Xue Yu Nao Ke Xue 21: 158-160, 2012 (In Chinese)

31. Fischer R and Maier O: Interrelation of oxidative stress and inflammation in neurodegenerative disease: role of TNF. Oxid Med Cell Longev 2015: 610813, 2015.

32. Warner-Schmidt JL and Duman RS: VEGF is an essential mediator of the neurogenic and behavioral actions of antidepressants. Proc Natl Acad Sci USA 104: 4647-4652, 2007.

33. Nowacka MM and Obuchowicz E: Vascular endothelial growth factor (VEGF) and its role in the central nervous system: A new element in the neurotrophic hypothesis of antidepressant drug action. Neuropeptides 46: 1-10, 2012.

34. Yu X: The effect of Tiandan capsule on VEGF, inflammatory cytokines and NSE of the patients with acute cerebral infarction. Xi Nan Jun Za Zhi She 13: 24-26, 2011 (In Chinese).

35. Qian XD, Luo CX and Zhu DY: Recent progress in neural stem cells transplantation. Zhong Guo Xi Bao Sheng Wu Xue Xue Bao 34: 212-217, 2012 (In Chinese).

36. Alfonso J, Frasch AC and Flugge G: Chronic stress, depression and antidepressants: Effects on gene transcription in the hippocampus. Rev Neuroscience 16: 43-56, 2005. 